\title{
First record of a parasitoid, Megaselia (M) scalaris (Diptera: Phoridae) of fall armyworm, Spodoptera frugiperda (J. E. Smith) (Lepidoptera: Noctuidae) from India
}

\author{
Sharanabasappa S. Deshmukh ${ }^{1 *}$ D, S. Kiran ${ }^{1}$, Atanu Naskar², Palam Pradeep ${ }^{1}$, C. M. Kalleshwaraswamy ${ }^{1}$ and \\ K. N. Sharath ${ }^{\text {}}$
}

\begin{abstract}
The fall armyworm (FAW), Spodoptera frugiperda (J. E. Smith) (Lepidoptera: Noctuidae), has become a major threat in maize cultivation since its invasion to India in 2018. The humpbacked fly, Megaselia scalaris (Loew) (Diptera: Phoridae), was recorded as a laboratory parasitoid of FAW, for the first time in India. Initially, 30-40 maggots of M. (M) scalaris emerged out from the dead pre-pupa and pupa of laboratory-reared FAW. The fly laid up to 15 eggs on the outer surface of 6th instar larva or pre-pupa of the FAW. The incubation period was 1-2 days. The fly had 3 larval instars which lasted 3-4 days and a pupal period of 10-11 days. The adults survived for 6-7 days.
\end{abstract}

Keywords: Megaselia scalaris, Parasitoid, Spodoptera frugiperda, Biology, Record, India

\section{Background}

Humpbacked flies or scuttle flies are the swift flying dipteran insects that belong to the family Phoridae. The species of this family like any other detritivores help to degrade the plant and animal matter (Disney 2008). The scuttle fly, Megaselia scalaris (Loew 1866), has been used as a model organism for biological control of insect pests. Its larval stage has been reported earlier as detritivores, facultative parasites, parasitoids, phytophagous, and coprophagous insect (Chakraborty et al. 2016). $M$. scalaris has been documented in many crops against various pests around the world (Harrison and Gardner 1991). Recently, the wide distribution of the fall armyworm (FAW), Spodoptera frugiperda (J. E. Smith) (Lepidoptera:

\footnotetext{
* Correspondence: sharanu.deshmukh@gmail.com

Scientific note: A new record of the parasitoid, Megaselia scalaris (Loew)

(Diptera: Phoridae) on the fall army worm, Spodoptera frugiperda (J. E. Smith)

(Lepidoptera: Noctuidae) in India

'Department of Entomology, College of Agriculture, University of Agricultural

and Horticultural Sciences, Shivamogga, Karnataka 577 204, India

Full list of author information is available at the end of the article
}

Noctuidae), has attracted many natural enemies. Among them, order Diptera serves as a natural controlling agent. In the year 2003, the survey's carried out in the America and Caribbean island reported Megaselia sp. as one of the larval parasitoid infesting late-instar larvae of FAW (Molina et al. 2003). Further, in Mexico, during 2007, natural exploration recorded $M$. scalaris as a unique parasitoid among the natural enemies documented on FAW in Mexico (Ruı'z-Na'jera et al. 2007).

The FAW is a notorious trans-boundary pest native to tropical and subtropical America (Sparks 1979). In January 2016, it was reported in Africa and spread to 44 countries in sub-Saharan Africa (Prasanna et al. 2018); later, it invaded India in May 2018 causing serious damage to maize plants (Sharanabasappa et al. 2018) and subsequently spread to southern states (Mahadevaswamy et al. 2018). Many natural enemies were reported from India (Sharanabasappa et al. 2019).

(c) The Author(s). 2021 Open Access This article is licensed under a Creative Commons Attribution 4.0 International License, which permits use, sharing, adaptation, distribution and reproduction in any medium or format, as long as you give appropriate credit to the original author(s) and the source, provide a link to the Creative Commons licence, and indicate if changes were made. The images or other third party material in this article are included in the article's Creative Commons licence, unless indicated otherwise in a credit line to the material. If material is not included in the article's Creative Commons licence and your intended use is not permitted by statutory regulation or exceeds the permitted use, you will need to obtain permission directly from the copyright holder. To view a copy of this licence, visit http://creativecommons.org/licenses/by/4.0/. 


\section{Methods}

The parasitoid was recorded for the first time in India from a field population of FAW, collected from Shivamogga district of Karnataka, near a village named Kudurekonda located $14.1365^{\circ} \mathrm{N}$ and $75.5306^{\circ} \mathrm{E}$, during September, 2020. The field collected larvae were reared under laboratory conditions at a temperature of $25^{\circ} \mathrm{C}$ and $75-80 \% \mathrm{RH}$. Later, adult parasitoids were noticed emerging out from the pupae of these field-collected larvae. The adult parasitoids were stored in $70 \%$ ethanol for identification at Diptera Section, ZSI, Kolkata. The biology of $M$. scalaris was studied on 5th or 6th instar larvae of FAW under laboratory conditions. Initially, the pupae of the parasitoid were collected from the infested culture of FAW. After adults' emergence from the pupae, a pair of adult parasitoids were released into 3 individual plastic boxes separately, each containing 5 head crushed (to avoid cannibalism) 6th instar FAW larvae, 5 pre-pupa, and 5 pupae, respectively. The parasitoid adults were provided 10\% honey solution as food. Further, rearing of the parasitoids was carried out as per methodology adopted by Chakraborty et al. (2016).

\section{Results}

Taxonomical identification Megaselia scalaris (Loew) (Diptera: Phoridae)

The materials examined are as follows: INDIA: Karnataka, Shivamogga, Kudurekonda, $14^{\circ} 7^{\prime} 59^{\prime \prime} \mathrm{N}, 75^{\circ} 30^{\prime} 48^{\prime \prime}$ E, 666 m, 15.ix. 2020, Coll. Sharanabasappa, ex. Fall armyworm $(3$ ㅇ, $3 \hat{\circ})$.

The adult fly was yellowish brown with many long bristles; the supra-antennal bristles were equidistant. The thorax was brownish dorsally, the prothoracic pleura had many small hairs and 2-4 long ventral bristles; the mesopleuron was lacking distinctive bristles, the scutum had indistinct brown markings having a pair of long bristles at the posterior margin; the scutellum had 2 pairs of bristles; legs were paler; the femur was enlarged, it was darker apically with dark brown small hairs, halters creamy yellowish, wings with half of the costal margin densely fringed; and the abdomen was darker brown (Fig. 1f, g).

\section{Preliminary biological data of Megaselia scalaris (Loew)}

As many as 30-40 maggots emerged out of the dead pre-pupae (Fig. 1a) and pupae of FAW. Two days post

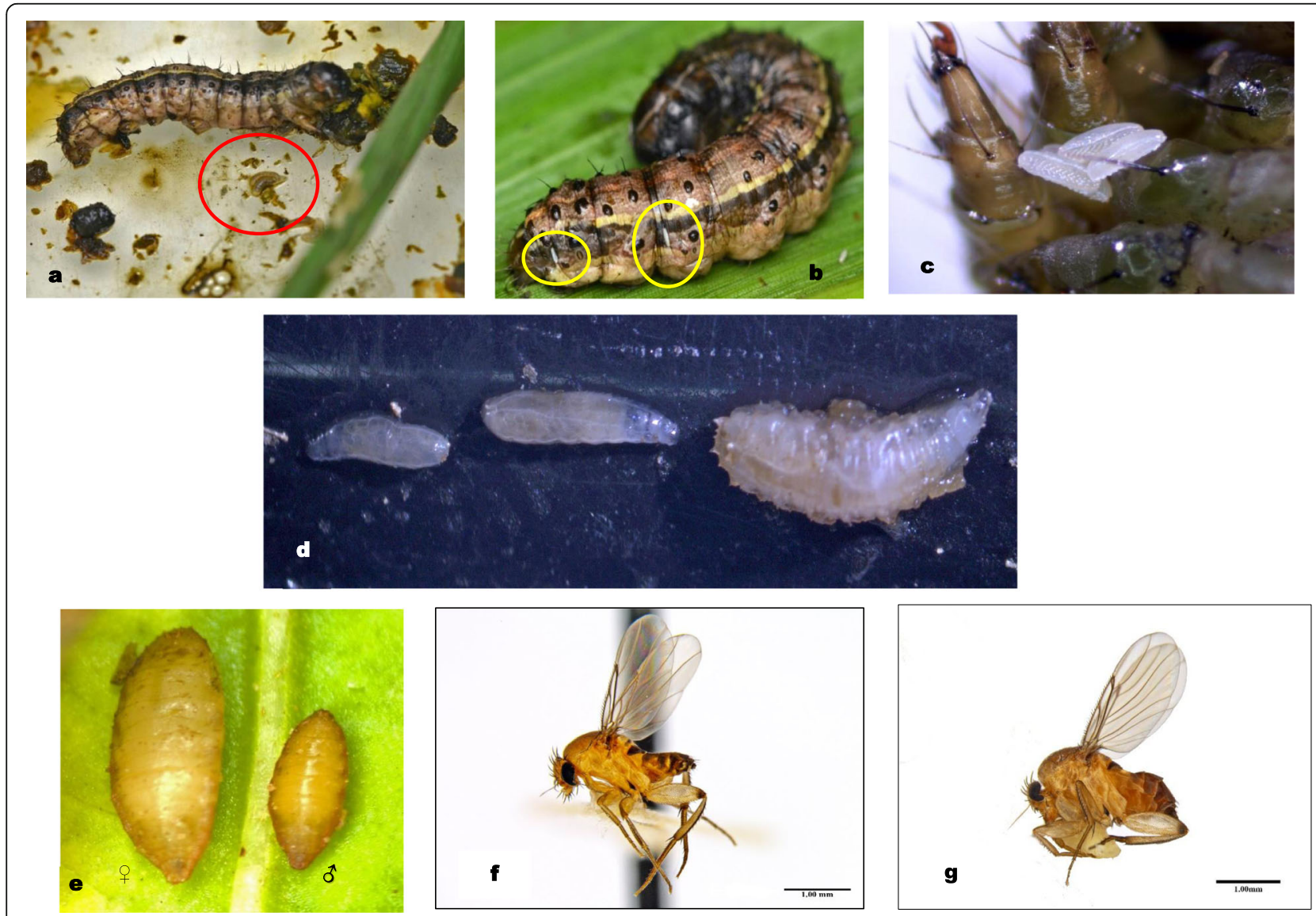

Fig. 1 Developmental stages of Megaselia scalaris. a Maggots emerging out of infested larva. b Eggs laid on later instar larva. c Eggs laid on prepupa. d Three instars of maggot. e Female and male pupa. f Adult male. g Adult female 
release, the oviposition by the parasitoids was observed on the outer surface of late-instar larvae in which they are about to pupate and also on pre-pupae and pupae. The adult fly laid pearl white coloured eggs of about 115 on the outer surface of the FAW 6th instar larvae (Fig. 1b) and pre-pupae (Fig. 1c). One to 2 days after egg-laying, creamy white maggots emerged. Three larval instars were recorded by mean durations of 1-2 days each (Fig. 1d). The pupa is of coarctate type, light brown in colour, with 2 pairs of spiracles observed on each end of the pupa (Amphineustic). Another interesting structure on the male and female pupae was the presence of respiratory tube or thoracic horn. The pupal period ranged from 10 to 11 days. Male and female pupae could be distinguished based on size (Fig. 1e). Usually, adult females were larger than the males. The fed adults' longevity on $10 \%$ honey solution ranged 6-7 days under laboratory conditions.

\section{Discussion}

This study is a new record of M. scalaris as a parasitoid of FAW in India; however, it has already been reported to infest FAW from the neighbouring country China (Tang et al. 2021). Eggs were found on the outer surface of 6th instar larvae or pre-pupae of FAW. Benner (1985) reported the female fecundity of about 1-100 matured eggs in one batch. In the present study, the female laid 1-15 eggs. The present study reported the emergence of 30-40 maggots from the pre-pupa and dead pupa of FAW. Similarly, El-Hawagry et al. (2021) had observed the emergence of 40-50 larvae per individual of parasitized Green stink bug, Nezara viridula. Three larval instars of M. scalaris were recorded, which are in line with the findings of Kaneko et al. (1978). The pupal period in the present study ranged from 10 to 11 days, which are dissimilar with findings of Benner and Ostermeyer (1980) who reported that male larvae of $M$. scalaris pupate 2 days earlier than the female larvae at $25^{\circ} \mathrm{C}$. Apart from the size, males and females can also be differentiated based on the modification of the last abdominal segment, i.e. narrow extension of 6th abdominal tergite (in case of female), and distinct terminalia that was easily distinguished in case of males (Brown and Oliver 2007).

\section{Conclusion}

The present study is just a new record of the parasitoid $M$. scalaris on FAW in India. Further studies on its parasitization of $M$. scalaris under laboratory and field conditions are needed.

Abbreviations

FAW: Fall armyworm; sp.: Species; Fig.: Figure; ZSI: Zoological Survey of India

\section{Acknowledgements}

We gratefully acknowledge the support, guidance, and encouragement of Director of Research, University of Agricultural and Horticultural Sciences,

Shivamogga, for valuable suggestions.

\section{Authors' contributions}

SSD, KS, KCM, and PP: data collection. SD, KS, KCM, and PP: original draft writing. SKN: manuscript editing and photographs. AN: species identification. All authors have read and agreed to the published version of the manuscript.

\section{Funding}

No funding received

Availability of data and materials

All data are available in the manuscript.

\section{Declarations}

Ethics approval and consent to participate

Not applicable

Consent for publication

Not applicable

Competing interests

The authors declare that they have no competing interests.

\section{Author details}

${ }^{1}$ Department of Entomology, College of Agriculture, University of Agricultural and Horticultural Sciences, Shivamogga, Karnataka 577 204, India. ${ }^{2}$ Diptera Section, Zoological Survey of India, Kolkata, West Bengal 700 053, India.

Received: 8 January 2021 Accepted: 8 June 2021

Published online: 17 June 2021

References

Benner DB (1985) Oocyte development and fecundity in Megaselia scalaris (Phoridae: Diptera). Int J Entomol Res 27(3):280-288

Benner DB, Ostermeyer EC (1980) Some observations on the life history of the fly Megaselia scalaris Loew (Phoridae) with special reference to the eclosion pattern. J Tenn Acad Sci 55(3):103-105

Brown BV, Oliver H (2007) First records of Megaselia scalaris (Loew) and M. spiracularis Schmitz (Diptera: Phoridae) from New Zealand, with additional information on other worldwide species. NZ Entomol 30:85-87

Chakraborty A, Naskar A, Parui P, Banerjee D (2016) Developmental variation of Indian thermophilic variety of scuttle fly, Megaselia (Megaselia) scalaris (Loew, 1866) (Diptera: Phoridae) on different substrates. Scientifica 2016:1-10. https://doi.org/10.1155/2016/4257081

Disney RHL (2008) Natural history of the scuttle fly, Megaselia scalaris. Ann Rev Entomol 53(1):39-60. https://doi.org/10.1146/annurev.ento.53.103106.093415

El-Hawagry MSA, Ebrahim AME, Nada MSE (2021) First detection of Megaselia scalaris (Loew) (Diptera: Phoridae) as a facultative endoparasitoid of Nezara viridula (L.) (Hemiptera: Pentatomidae). Egypt J Biol Pest Control 31(1):1-7

Harrison RD, Gardner WA (1991) Parasitism of the pecan weevil (Coleoptera: Curculionidae) by Megaselia scalaris (Diptera: Phoridae). J Entomol Sci 26(3): 301-302. https://doi.org/10.18474/0749-8004-26.3.301

Kaneko K, Furukawa E, Kusui Y (1978) Studies on phorid flies (Phoridae, Diptera) in Japan. Part III. New record of Megaselia scalaris (Loew, 1866), collected from Japan. J Aichi Med Univ Ass 6:261-265

Mahadevaswamy HM, Asokan R, Kalleshwaraswamy CM, Sharanabasappa D, Prasad YG, Maruthi MS, Shashank PR, Ibemu Devi N, Surakasula A, Adarsha S, Srinivas A, Rao S, Vidyasekhar SRM, Shyam Sunder Reddy G, Nagesh SN (2018) Prevalence of "R" strain and molecular diversity of fall armyworm, Spodoptera frugiperda (J.E. Smith) (Lepidoptera: Noctuidae) in India. Indian J Entomol 80(3):544-553

Molina OJ, Carpenter JE, Heinrichs EA, Foster JE (2003) Parasitoids and parasites of Spodoptera frugiperda (Lepidoptera: Noctuidae) in the Americas and Caribbean basin: an inventory. Fla Entomol 86(3):254-289. https://doi.org/10.1 653/0015-4040(2003)086[0254:PAPOSF]2.0.CO;2 
Prasanna BM, Huesing JE, Eddy R, Peschke VM (eds) (2018) Fall Armyworm in Africa: a guide for integrated pest management. USAID, CIMMYT, Mexico

RuI'z-Na'jera RE, Molina-Ochoa J, Carpenter JE, Espinosa-Moreno JA, Ruíz-Na'jera JA, Lezama-Gutie'rrez R, Foster JE (2007) Survey for Hymenopteran and Dipteran Parasitoids of the Fall Armyworm (Lepidoptera: Noctuidae) in Chiapas, Mexico. J Agric Urban Entomol 24(1):35-42

Sharanabasappa D, Kalleshwaraswamy CM, Asokan R, Swamy HM, Maruthi MS, Pavithra HB, Hegde K, Navi S, Prabhu ST, Goergen G (2018) First report of the fall armyworm, Spodoptera frugiperda (J E Smith) (Lepidoptera: Noctuidae) an alien invasive pest on maize in India. Pest Manage Hortic Ecosyst 24(1):23-29 Sharanabasappa D, Kalleshwaraswamy CM, Poorani J, Maruthi MS, Pavithra HB, Diraviam J (2019) Natural enemies of Spodoptera frugiperda (J. E. Smith) (Lepidoptera: Noctuidae), a recent invasive pest on maize in South India. Fla Entomol 1029(2):619-623

Sparks AN (1979) Review of the biology of the fall armyworm. Fla Entomol 62(2): 82-87. https://doi.org/10.2307/3494083

Tang Y, Li Q, Xiang L, Gu R, Wu Y, Zhang Y, Zhou Z (2021) First report on Megaselia scalaris Loew (Diptera: Phoridae) infestation of the invasive pest Spodoptera frugiperda Smith (Lepidoptera: Noctuidae) in China. Insects 12(1): 65. https://doi.org/10.3390/insects12010065

\section{Publisher's Note}

Springer Nature remains neutral with regard to jurisdictional claims in published maps and institutional affiliations.

\section{Submit your manuscript to a SpringerOpen ${ }^{\circ}$ journal and benefit from:}

- Convenient online submission

- Rigorous peer review

- Open access: articles freely available online

- High visibility within the field

- Retaining the copyright to your article

Submit your next manuscript at $\boldsymbol{\nabla}$ springeropen.com 